\title{
NETopathies? Unraveling the Dark Side of Old Diseases through Neutrophils
}

\author{
Alexandros Mitsios ${ }^{1 \dagger}$, Athanasios Arampatzioglou ${ }^{1 \dagger}$, Stella Arelaki ${ }^{1,2 \dagger}$, loannis Mitroulis ${ }^{3}$ and \\ Konstantinos Ritis ${ }^{1,4 *}$ \\ 1 Laboratory of Molecular Hematology, Democritus University of Thrace, Alexandroupolis, Greece, ${ }^{2}$ Department of Pathology, \\ University General Hospital of Alexandroupolis, Alexandroupolis, Greece, ${ }^{3}$ Department of Clinical Pathobiochemistry, Institute \\ for Clinical Chemistry and Laboratory Medicine, Faculty of Medicine Technische Universität Dresden, Dresden, Germany, \\ ${ }^{4}$ First Department of Internal Medicine, University Hospital of Alexandroupolis, Democritus University of Thrace, \\ Alexandroupolis, Greece
}

OPEN ACCESS

Edited by:

Marko Radic,

University of Tennessee, USA

Reviewed by:

Huw Lewis,

GlaxoSmithKline, UK

Moritz Leppkes,

Universitätsklinikum Erlangen,

Germany

*Correspondence:

Konstantinos Ritis

kriti@@med.duth.gr

tThese authors have contributed equally to this work.

Specialty section: This article was submitted to

Molecular Innate Immunity,

a section of the journal

Frontiers in Immunology

Received: 24 August 2016 Accepted: 21 December 2016

Published: 11 January 2017

Citation:

Mitsios A, Arampatzioglou A,

Arelaki S, Mitroulis I and Ritis K (2017) NETopathies? Unraveling the Dark Side of Old Diseases through

Neutrophils.

Front. Immunol. 7:678. doi: 10.3389/fimmu.2016.00678
Neutrophil extracellular traps (NETs) were initially described as an antimicrobial mechanism of neutrophils. Over the last decade, several lines of evidence support the involvement of NETs in a plethora of pathological conditions. Clinical and experimental data indicate that NET release constitutes a shared mechanism, which is involved in a different degree in various manifestations of non-infectious diseases. Even though the backbone of NETs is similar, there are differences in their protein load in different diseases, which represent alterations in neutrophil protein expression in distinct disorder-specific microenvironments. The characterization of NET protein load in different NET-driven disorders could be of significant diagnostic and/or therapeutic value. Additionally, it will provide further evidence for the role of NETs in disease pathogenesis, and it will enable the characterization of disorders in which neutrophils and NET-dependent inflammation are of critical importance.

Keywords: neutrophil extracellular traps, neutrophil, thromboinflammation, autoimmunity, autoinflammation

\section{INTRODUCTION}

Neutrophils constitute an essential part of the innate immune system in host defense against pathogens, as shown more than 100 years ago $(1,2)$. Circulating neutrophils are recruited in vast numbers at the sites of infection or sterile inflammation, in response to a variety of pathogen and host-derived inflammatory mediators (3). There, via adhesive interactions with endothelial cells, neutrophils rapidly infiltrate the site of inflammation (4). Uncontrolled inflammation in turn results in the release of newly produced neutrophils from the bone marrow, in a process termed as emergency granulopoiesis (5).

In addition to phagocytosis and degranulation, it has been recently proposed that neutrophils employ an additional strategy, in order to restrain infection: the release of NETs $(1,2,6,7)$.

Neutrophil extracellular traps are extracellular chromatin structures, formed upon certain inflammatory stimuli and composed of cytoplasmic, granular, and nuclear components of neutrophils $(1,2,6,7)$. To date, it is known that they can entrap and possibly kill pathogens. It has been shown that NETs bind bacteria $(6,8,9)$ as well as fungi $(10)$. The antimicrobial activity of NETs relies on both cytoplasmic and granular proteins as well as histones. This suggests that the intact NET structure is 
crucial for their antimicrobial function, enabling the increased local concentration of antimicrobial factors $(1,2,6,7,11)$.

Besides their role in infectious disorders, studies carried out after 2008 support the role of NETs in the pathophysiology of non-infectious diseases, such as thrombosis (12-16), autoimmune diseases $(14,17-22)$, genetically driven autoinflammatory (23), and other inflammation-related diseases (24-26), metabolic disorders $(27,28)$, lung diseases (29-32), fibrosis (33), and cancer (34-36).

Herein, we seek to review current data regarding the proposed role of NETs in non-infectious human diseases. We also discuss the existing evidence supporting that these structures constitute a common mechanism of the pathophysiology of distinct diseases.

\section{MECHANISM OF NET FORMATION}

Despite the morphological similarities of NETs released by neutrophils in response to different stimuli and under diverse conditions, it is nowadays widely accepted that there is more than one mechanism involved in NET release (37). Additionally, mitochondrial DNA also contributes in NET formation $(38,39)$, whereas, even though in vitro NET formation leads to cell death
(40), it is reported that neutrophils that undergo NET release in vivo may remain active and functional, suggesting that NET formation may not necessarily be a terminal event $(41,42)$.

Activated neutrophils undergo dramatic morphological changes in order to release NETs (43-47). The nuclear and granular membranes disintegrate and elastase enters into the nucleus, followed by hypercitrullination of histones, chromatin decondensation into the cytoplasm, rupture of the plasma membrane, and extrusion of nuclear material from the cell into the extracellular space (43-47). The enzymes peptidyl arginine deiminase type IV (PAD4), neutrophil elastase (NE), and myeloperoxidase (MPO) have been implicated in the initial chromatin decondensation and in the degradation of the nuclear envelope (43-47). As a final step, extracellular DNA, histones, and granular enzymes form a network of NETs that entrap endogenous (e.g., platelets) and extrinsic (e.g., bacteria) particles and molecules (Figure 1A) (43-47). The negatively charged DNA acts as the backbone of the NET, interacting with other NET components through positive electrostatic charge (43-47). As it has been recently described, this scaffold is crucial for NET proteins to maintain their function $(6,43,47)$, since dismantling of NET structures by DNase abolishes their antimicrobial activity (6). However, in the majority of

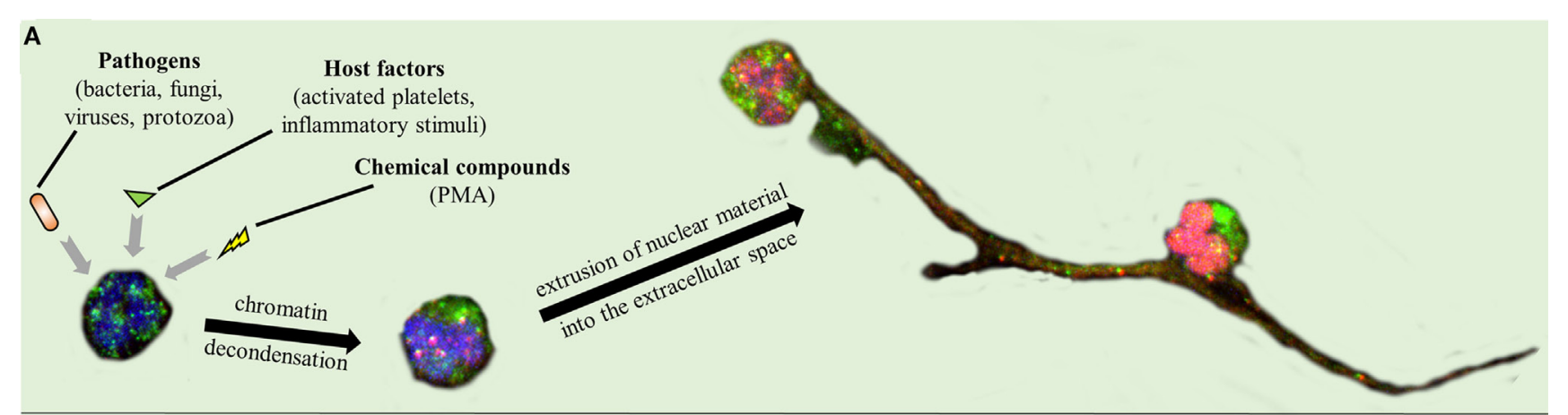

B

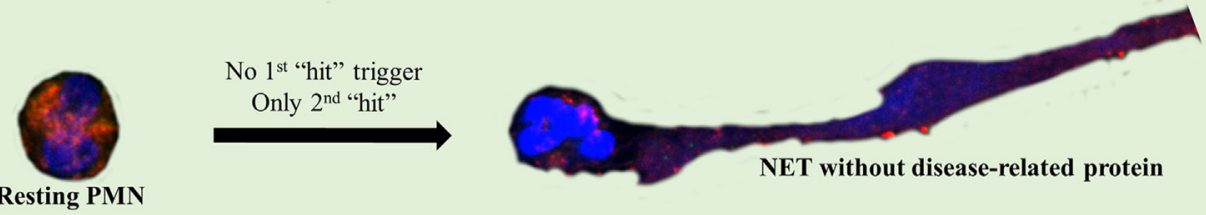

c

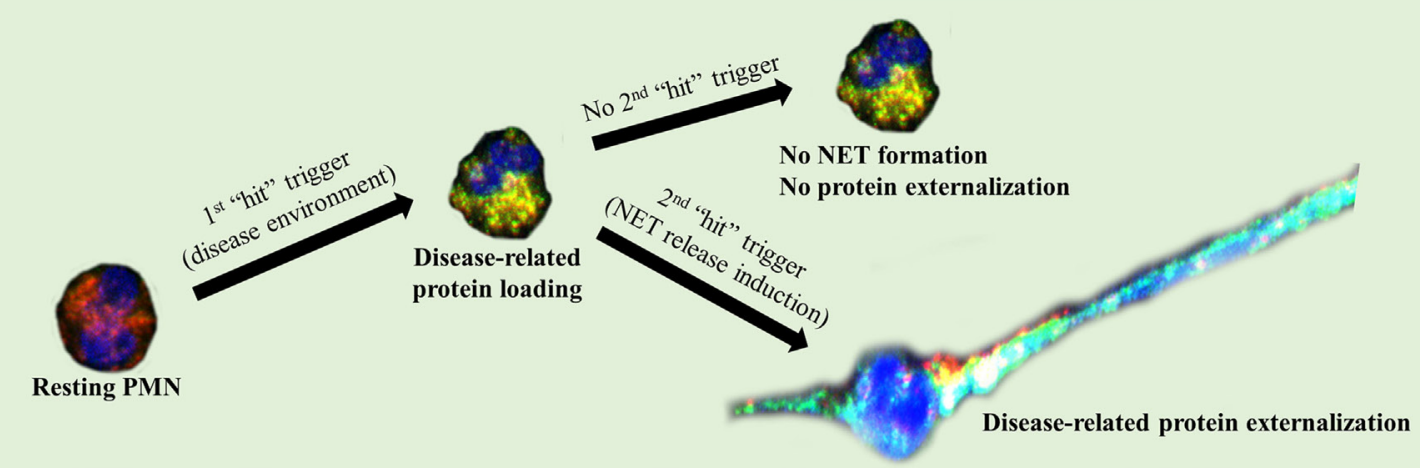

FIGURE 1 | Neutrophil extracellular trap (NET) formation and protein decoration. Representative images taken using confocal microscopy, demonstrating (A) NET formation mechanism and (B,C) the two-step process through which the disease-related protein is externalized. 
these studies, PMA was used as a NET inducer $(48,49)$. Based on the criticism directed against the use of PMA as a NET inducer, the exact intracellular pathway that leads to NET release is still unclear (50).

At the molecular level, NET formation is still poorly understood and it is not defined whether neutrophils employ a similar mechanism to release NETs under different circumstances. However, there is strong evidence that the production of reactive oxygen species (ROS), the relocation of NE and MPO into the nucleus, histone citrullination, and eventually the rupture of the plasma membrane are, sequentially, involved in NETosis (43-47).

Cell metabolism has major contribution in immune cell function (51), including neutrophil activation. Neutrophils rely mainly on glycolysis for their metabolic needs, enabling their adaptation to the highly hypoxic inflammatory sites $(52,53)$.

Moreover, there is evidence that the metabolic shift to the pentose phosphate pathway is important for NET release, due to the involvement of glucose-6-phosphate dehydrogenase in fueling NADPH oxidase- 2 with NADPH, to produce an effective amount of ROS and thus induce NETs. In contrast, mitochondrial ROS release, which is NADPH-independent, is not effective in signaling for NET production $(54,55)$.

Additionally, NET formation has been shown to require, at least in certain circumstances, the activation of autophagy (56). Autophagy is an anti-apoptotic mechanism activated in response to cell stress, in order to regulate protein and organelle turnover, ensuring cell survival (57). The protein kinase mammalian target of rapamycin (mTOR) negatively regulates autophagy, involved also in NET formation $(58,59)$. We and others $(23,24,33,56$, 60-62) have shown that blocking autophagy through PI3K signaling, either at the initial levels by using 3-methyladenine (24, 60-62) or at the level of autophagosomal acidification by using wortmannin or bafilomycin $(23,33,56,62)$, inhibits the induction of NET release. However, more mechanistic studies are needed to identify how autophagy is involved in NET release, even though mTOR signaling and ROS production have been linked to both processes $(7,56,59)$.

It is suggested that autophagy is crucial for NET release in both infectious and non-infectious diseases, including sepsis, familiar Mediterranean fever (FMF), gout, and inflammatory-driven fibrosis $(12,23,56)$.

\section{CAN NET CARGO DEFINE NEUTROPHIL ROLE IN DISEASE?}

Independently of the stimulus, NETs are composed of DNA, citrullinated histone 3 (cit-H3), NE, and MPO, the three main proteins commonly used for their detection $(43-45,47)$. Even though a proteomic analysis of infiltrating neutrophils in diverse tissues and in different disorders could be the proof of concept, there is evidence proposing that neutrophils express and release in the form of NETs a variety of proteins, depending on the specific inflammatory environment (63). For example, tissue factor (TF) was detected on NETs in vein and arterial thrombosis $(16,64,65)$, interleukin 1 beta (IL-1 $\beta$ ) in gouty arthritis (24) and FMF (23), interleukin 17 (IL-17) in psoriasis (66) and pulmonary fibrosis
(33), antimicrobial peptide LL-37 in systemic lupus erythematosus (SLE) (19), and PAD4 in rheumatoid arthritis (RA) (67).

Even though NETs constitute a common event in distinct pathophysiologic conditions, the expression of distinct bioactive proteins on NETs in different disorders might be the one that determines their specific function in disease pathogenesis.

A two-"hit" process has been proposed to explain the differential protein cargo of NETs in distinct disorders. The first "hit" in this process is the disease-specific environment that primes neutrophils to express disease-associated protein. A second "hit" is then required for the induction of NET formation (Figures 1B,C). However, this is a simplified model, and we cannot exclude the possibility that the same stimulus can drive both events. A typical paradigm of this two-"hit" model has been described in ST-segment elevation acute myocardial infarction (16). It has been shown in acute coronary syndromes that a variety of inflammatory stimuli trigger the cytoplasmic expression of TF in circulating neutrophils. At sites of atherosclerotic plaque rupture, locally activated platelets interact with TF-loaded neutrophils leading to the release of TF-bearing NETs inside the affected artery. The release of functional TF on NETs is able to further induce thrombin generation and platelet activation, creating a possible vicious cycle, that leads to thrombus propagation and stability (16).

The expression of these "disease-related" proteins on NETs could increase their local bioactivity $(12,14,16,23,66,68)$. On the other hand, it has been shown that, at high densities, NETs limit inflammation by degrading cytokines and chemokines (69). This balance between the pro-inflammatory and prothrombotic role of NETs, though the expression of cytokines like IL- $1 \beta$ and IL-17, and their anti-inflammatory role, could be exploited for the development of new therapeutic approaches.

In the following section, we review the clinical and experimental data that link NETs with pathogenesis of several disorders. Even though the list of diseases in which NETs have been identified is extensive, we believe that the further characterization of the degree of NET involvement in such disorders could enable the classification of diseases in which NETs have a definite and strong involvement under the term of "NET-driven disorders" or "NETopathies." The term NETopathy(ies) is derived from the abbreviation NET and the Greek word $\pi$ ó $\theta$ os $=$ pathos, which means disorder.

\section{NETs in Thromboinflammation}

The widely accepted cross talk between inflammation and thrombosis has led to the introduction of the term thromboinflammation (68). Cells of the hematopoietic system, including neutrophils, platelets, and monocytes, have a major role in this process (64). There is increasing evidence implicating NET release with the development of both vein and arterial thrombosis $(12,14,16,26$, $65,70-77)$. Extracellular deposition of DNA co-localized with neutrophil granule proteins has been shown in thrombi from patients with deep vein thrombosis (DVT) (78), especially at the phase of organization of the thrombus (70). Additionally, circulating extracellular DNA in the form of nucleosomes and DNA associated with neutrophil granule proteins, supporting the induction of NET release, has been identified in blood samples from 
patients with DVT $(79,80)$. Similarly, NETs have been identified in thrombus specimens from patients undergoing thrombectomy in the context of myocardial infarction $(15,16,62,71)$. In a recent multicenter study in patients presenting with stent thrombosis, neutrophils were the more abundant leukocyte population in thrombus specimens, whereas NETs were identified in $23 \%$ of thrombi (71). Regarding specific disorders associated with thrombotic manifestations, NETs in thrombus specimens and/ or increased levels of nucleosomes have been identified in disseminated intravascular coagulation in sepsis (73), in paroxysmal nocturnal hemoglobinuria (81), thrombotic microangiopathies (82), antiphospholipid syndrome (APS) (74), antineutrophil cytoplasmic antibody (ANCA)-associated vasculitis (AAV) (14), or hemodialysis-related thrombogenicity (83). These clinical data support a role for NETs in the development of both arterial and venous thrombosis.

The prothrombotic role of NETs was further confirmed in several experimental animal models. NETs were observed in thrombi, in a baboon model (75) and in several mouse models of DVT $(64,76,84)$. In a mouse model of DVT, infusion of DNase I resulted in protection from thrombosis (76), whereas $\mathrm{PAD}^{-/-}$mice were protected from thrombosis (85), supporting the pathogenetic role of NETs in venous thrombosis, at least in this animal model. The in vivo role of NETs in the development of thrombosis was further shown in a mouse model of APS (86). Additionally, NETs contribute in cancer-induced venous thrombosis, as shown in a mouse model of chronic myelogenous leukemia (34) and in the RIP1-Tag2 model of insulinoma and MMTV-PyMT model of breast cancer (77). Brill et al. linked histones with the prothrombotic effect of NETs, since histone infusion also resulted in thrombosis. However, there is evidence that NETs participate in DVT via interaction with von Willebrand factor, a factor that potentially activates platelets (76). Furthermore, it has been reported that in a mouse model of DVT TF triggers intraluminal fibrin formation, while the release of NETs activates factor XII, consolidating DVT (64). The involvement of NET-bound TF, which is the main in vivo initiator of coagulation (87), in NET-dependent thromboinflammation has been shown in several studies, since TF has been identified in NETs released in neutrophils from patients with sepsis, APS, AAV, or myocardial infarction $(12,14,16,74)$ or in a mouse model of DVT (64).

The interplay between neutrophils and platelets has been shown to have a major contribution in NET release $(16,62,72$, $84,88)$. Clark et al. have shown that upon toll-like receptor 4 (TLR4) activation platelets induce the formation of NETs in a mouse model of sepsis (72). This leads not only to bacterial but also to platelet entrapment in NETs, resulting in tissue damage (72). Several studies have further identified platelet derived high mobility group box 1 (HMGB1) as the factor that mediates platelet-neutrophil interaction and NET release $(62,84)$. HMGB1 released by platelets has been shown to promote thrombosis in a mouse model of DVT (84), whereas it mediates neutrophil activation in the context of myocardial infarction (62). The importance of platelet-neutrophil interaction is prominent in coronary artery thrombosis, since it was proved that coronary thrombi are mainly composed of interacting neutrophils and platelets $(16,62)$. The rupture of the atherosclerotic plaque primes a cascade of events, which results in platelet activation and NET release, leading to thrombus formation and blood vessel occlusion. The expression of TF on NETs may propagate the further activation of the coagulation system, leading to thrombus expansion (16).

Taken together, there is strong evidence, derived by clinical and experimental observation, that neutrophils and NETs are major players in both venous and arterial thrombosis. The development and clinical use of factors that target NETs could provide, however, the definite proof for the role of NETs in thrombotic disorders.

\section{NETs in Autoimmune Diseases}

A growing number of studies demonstrate that NETs play a driving role in the pathogenesis of a variety of autoimmune disorders, such as SLE, AAV, RA, and psoriasis. In the aforementioned disorders, NETs are a main source of autoantigens, are present in excess amount, or are decorated with disease-specific proteins.

\section{Systemic Lupus Erythematosus}

Systemic lupus erythematosus is a systemic autoimmune disease and a well-studied model. SLE is characterized by systemic production of autoantibodies against a plethora of intracellular and extracellular targets. These autoantibodies are able to cause extensive tissue damage $(89,90)$.

There is evidence supporting the involvement of NETs in the pathophysiology of SLE. It has been shown that NETs are directly associated with the severity and the progression of the disease (91-95). Neutrophils from SLE patients are primed to undergo NET release $(17,96)$. Autoantibodies and more specifically antibodies against LL-37 have been shown to activate neutrophils for NET release $(18,19)$. On the other hand, NETs are composed of DNA, histones, and proteins-like LL-37, providing a possible source of autoantigens for the development of lupus-specific autoantibodies (Figure 2B) (17-19, 97-99). Interestingly, Villanueva et al. reported a neutrophil subpopulation in SLE, termed as low-density granulocytes (LDG), prone to release NETs, which promote vascular damage $(18,91,100)$. It was further demonstrated that LL-37-bearing NETs fuel the immune response in SLE by activating plasmacytoid dendritic cells (pDCs) in an Immunoglobulin-Fc region receptor II-a (FcRIIa) and TLR9-dependent manner. This leads to interferon alpha (IFN $\alpha$ ) production, which is a critical player in the pathogenesis of SLE. Furthermore, IFN $\alpha$ triggers NET generation and activates $\mathrm{T}$ and $\mathrm{B}$ cells leading to the production of antibodies against NETs, creating a vicious cycle $(19,97,101,102)$.

Interestingly, there is a disease-associated defect in the clearance of NETs, due to the reduced activity of DNase I and the increased amounts of DNase I inhibitors (17, 20, 94, 103-106), supporting the hypothesis that dysregulation of NET clearance may be one of the initial steps that lead to lupus-specific autoantibody production.

\section{ANCA-Associated Vasculitis}

Antineutrophil cytoplasmic antibody-associated vasculitis is described as a group of autoimmune diseases, characterized by the presence of autoantibodies against the neutrophil granule 


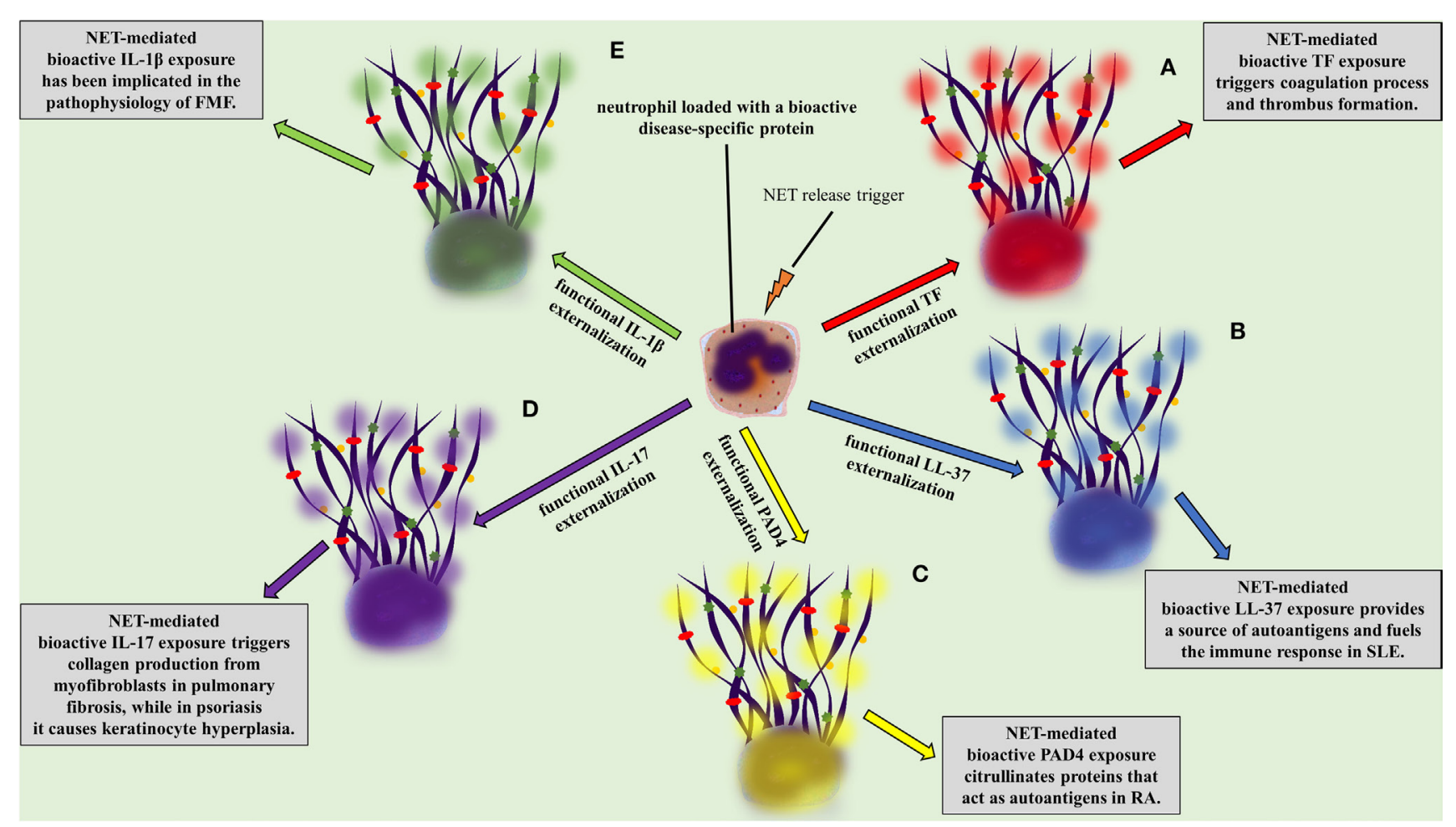

FIGURE 2 | NETopathies are ruled by the bioactive disease-related neutrophil extracellular trap (NET) proteins. The clinical manifestations of (A) thrombosis, (B) systemic lupus erythematosus, (C) rheumatoid athritis (RA), (D) pulmonary fibrosis and psoriasis, (E) familiar Mediterranean fever are determined by the NET-mediated exposure of bioactive disease-related proteins.

proteins, such as proteinase 3 (PR3) and MPO. The study by Kessenbrock et al. provided the initial evidence for the link between NETs and AAV. In this study, the intraglomerular deposition of NETs in biopsies from patients with small-vessel vasculitis was shown. Additionally, it was shown that neutrophils release NETs when activated with ANCA (107). Further studies confirmed the deposition of NETs in affected tissues from patients with $\operatorname{AAV}(14,61,108-110)$, whereas increased levels of circulating NET remnants were observed in patients with AAV $(14,22)$. Additionally, a recent study correlated AAV disease activity with the presence of NET-prone LDGs in peripheral blood (110). NETs were further associated with the AAV hypercoagulability, since NETs released during active disease are loaded with TF [Figure 2A $(14,111)$.

Since PR3 and MPO are abundantly present in NETs, it has been proposed that NETs mediate the extracellular exposure of these potential autoantigens, having an important role in the initiation of the disease $(17,20,21,107)$. Sangaletti et al. have shown that myeloid DCs can acquire neutrophil proteins released in the form of NETs. Furthermore, immunization of mice with DCs co-cultured with NET remnants resulted in the development of MPO-ANCA and renal vasculitis (112). A common characteristic between SLE and AAV is the decreased degradation of NETs, attributed to the reduced activity and inhibition of DNase I, as well as to the protection over NETs by autoantibodies and components of the complement $(17,20,107)$.

\section{RA and Psoriasis}

Rheumatoid arthritis is a chronic autoimmune disease that affects synovial joints. It is known that neutrophils are the most abundant cell type of synovial fluid in RA patients (113).

Recent studies identified the presence of NETs in the circulation and the release of NETs by synovial neutrophils (114, 115). Khandpur et al. have shown that TNF, IL-17, and anticitrullinated protein antibodies (ACPA) promote NET release by neutrophils from patients with RA, whereas therapeutic blockade of TNF function has been shown to decrease the extensive NET generation that characterizes RA patients. Of interest, IL-17 was able to promote NET release only in neutrophils from patients with RA, which implies that the disease-specific inflammatory microenvironment primes neutrophils for NET formation (115).

Recent studies highlight that citrullinated histones in NETs consist autoantigens that stimulate and participate in the outset of the excessive inflammation, and more specifically in ACPA immune response, in RA $(18,115)$. It has been further demonstrated that RA-driven NETs are decorated with enzymatically active PAD4, which possibly further citrullinates targets, rendering them autoantigens (Figure 2C) $(49,67,116)$. Finally, NETs in RA indirectly participate in the stimulation of distinct cell types, such as fibroblast-like synoviocytes, which invade and damage cartilage in RA $(115,117)$.

The possible involvement of NETs in the pathogenesis of psoriasis has been also proposed. Psoriasis is an autoimmune 
skin disorder characterized by epidermal hyperplasia and neutrophil infiltration in the epidermis. Neutrophils are involved in the pathophysiology of psoriasis, linking innate and adaptive immune system, and acting as a main source of IL-17 (66, 118, 119).

Interleukin 17 has a significant role in the pathophysiology of psoriasis causing keratinocyte hyperplasia $(119,120)$, whereas therapeutic administration of antibodies against IL-17 is efficacious in the treatment for psoriasis (121-123). The externalization of IL-17 in a bioactive form is feasible through NET formation (Figure 2D) $(66,124)$, which has been also observed in models of RA (115) and pancreatitis (125). The fact that the active form of IL-17 lies on NETs renders it an easily accessible target.

Taken together, a significant amount of evidence suggests that NETs contribute in the pathogenesis of several autoimmune disorders, acting either at the initiation of disease, providing a source of autoantigens, or promoting tissue injury $(66,90,93,107,109,115)$. There are reports suggesting that NETs can activate other inflammatory cell populations and promote the activation of the adaptive immune system $(97,102$, 115). However, whether the specific structure of NETs and the possible modification in proteins loaded on NETs have a major impact in the break of tolerance and induction of autoimmunity still remains elusive.

\section{NETs in Autoinflammatory Diseases}

Recent studies revealed a possible role for NETs in the inflammatory response that governs autoinflammatory syndromes, including gout and FMF.

Gout is an autoinflammatory type of arthritis caused by the intra-articular deposition of monosodium urate crystals (MSU crystals). The deposition causes inflammatory attacks due to innate immunity activation (126-129). Additionally, the chronic form of the disease is characterized by tophus formation, causing mechanical destruction of the joint (130). It has been shown that MSU crystals cause a strong induction of NETs $(24,131)$ which, in high neutrophil concentrations, ameliorates MSU crystal-induced inflammation by promoting the degradation of inflammatory cytokines and chemokines in a mouse model of MSU-induced inflammation $(69,132)$. Despite their protective role, NETs indirectly engender the destruction of the joint by easing the packing of MSU crystals and the formation of tophi $(69,132)$. However, whether NETs support the initiation of gouty inflammation in humans remains unanswered.

Familiar Mediterranean fever is a hereditary autoinflammatory disorder, characterized by inflammatory attacks and neutrophil infiltration into the affected sites (23). Moreover, it is an IL-1 $\beta$-mediated disease, and this is clear due to the fact that IL-1 $\beta$ blockade constitutes an emerging treatment in FMF (23, 133, 134). During FMF attacks, neutrophils undergo excessive NET formation, which decreases after the inflammation dissolution (23).

During FMF attacks increased levels of circulating MPODNA complexes are detected, suggesting the release of NETs in the systemic circulation, whereas their levels normalize during the resolution phase of the disease (23). The detection of bioactive IL-1 $\beta$ in NETs released ex vivo by patient neutrophils or control neutrophils treated with FMF attack serum implies that neutrophils serve as critical effector cells in the amplification of inflammation in FMF (Figure 2E) (23).

\section{NETs in Metabolic Disorders}

In type II diabetes (T2D), immunological changes lead to altered levels of cytokines and changes in both number and activation status of various leukocytes, including neutrophils (135). Until recently, it was thought that inflammatory responses may have a dual role in $\mathrm{T} 2 \mathrm{D}$, as they seem to have a causal relationship leading to resistance to insulin, while on the other hand they seem to be intensified by the hyperglycemic state, resulting in T2D complications (135).

Bearing in mind that diabetes affects neutrophil count and activity, that hyperglycemia-driven oxidative stress facilitates diabetic complications, and that neutrophils generate oxidative stress in diabetes, it was assumed that a dysregulation in NETosis may represent the link among hyperglycemia, oxidative stress, inflammation, and diabetic complications (27). In this direction, a recent study demonstrated that high glucose in vitro and hyperglycemia in vivo induce release of NETs and their products (27). Another study provided evidence that hyperglycemic conditions lead to the formation of short-lived and unstable NETs, while also prime neutrophils and constitutively activate NET formation, leading to reduced response to subsequent external stimuli (136). Thus, it was hypothesized that neutrophils primed due to hyperglycemia may not respond to further external stimulus in T2D patients, making them susceptible to infections (136). Finally, a third study demonstrates that, in T2D patients, dysregulated NET release caused by hyperglycemia is responsible for impairment of wound healing as well as for diabetic complications (137). Even though these studies support a role for NETs in T2D, it is not clear to what extent manipulation of neutrophils could ameliorate or prevent diabetic complications.

Moreover, there is evidence that neutrophils and NETs have a potential role in the pathogenesis of type I diabetes $(28,138,139)$; however, their implication in the onset and/or the development of this disease has not been investigated so far.

\section{NETs in Lung Diseases and Fibrosis}

Neutrophil extracellular traps have been implicated in inflammatory lung diseases and inflammatory-derived fibrosis (33). Several inflammatory lung diseases are characterized by the migration and detection of neutrophils and monocytes in the airway lumen and the bronchoalveolar lavage fluid (140). NETs have been associated with inflammatory diseases, such as chronic obstructive pulmonary disease (COPD), cystic fibrosis $(\mathrm{CF})$, acute lung injury, acute respiratory distress syndrome, and asthma $(29,30)$.

Cystic fibrosis is characterized by abundant free DNA structures in airway fluids that increase the viscosity of the sputum and lead to airflow obstruction and tissue damage. Free DNA originates mainly from NETs released from neutrophils that are recruited to the area in an effort to kill the bacterial burden, but they finally contribute to the damage of lung tissue $(31,32)$. Additionally, it has been proved that NE plays an equally important role in CF, leading to tissue damage, especially in patients 
under treatment that are characterized by increased DNA cleavage (141). Recombinant human deoxyribonuclease (rhDNase) is an adjunctive to antibiotics treatment for patients with CF over the last two decades, showing a beneficial effect at least in a subpopulation of patients with CF $(142,143)$. Moreover, it has been reported that DNase I and histone-blocking antibodies have been used in mice against transfusion-related acute lung injury, in which NETs play a crucial role (144). Inhibition of either NE or NET release in general could be a novel future therapeutic strategy in patients with CF $(141,145)$.

There is evidence that the inflammatory microenvironment developed in chronic lung diseases including COPD and interstitial lung disease contributes either to localized or to generalized fibrosis, respectively. Specific fibrosis-related agents, such as cigarette smoke, magnesium silicate, and bleomycin, stimulate neutrophils to undergo NETosis. NETs indirectly regulate fibrosis by activating lung fibroblasts and differentiating them into myofibroblasts, through autophagy and histone hypercitrullination. Subsequently, NET remnants, such as IL-17, regulate connective tissue growth factor (CCN2) expression and collagen production by the differentiated fibroblasts and not their differentiation (Figure 2D). However, NET degradation significantly restricts these effects, indicating that it could be possibly used as a restraining mechanism against fibrosis (33).

\section{NETs in Cancer}

In the last few years, NETs have redefined the role of neutrophils in tumor biology $(34-36,146-150)$. It is suggested that NETs may act within the primary tumor promoting tumor progression (146-148), while at remote sites they might sequester circulating cancer cells favoring metastasis $(35,36,149)$. Additionally, NETs have been implicated in cancer-associated thrombosis $(34,147)$.

There is increasing evidence supporting that, in both experimental models and cancer patients, NET deposition in the tumor mass is associated with tumor progression $(35,146,150-153)$. A finding that supports the implication of NETs in tumor biology is that tumor cells predispose neutrophils to undergo NETosis (34, 146). Moreover, in the tumor microenvironment, NETs interact with tumor cells and expose them to bioactive proteins, possibly favoring their survival through induction of proliferation and inhibition of apoptosis, as well as supporting their escape from the primary tumor (148).

Excessive NET deposition leads to a persistent inflammatory state (154-156), which in cancer probably promotes the expression of adhesion molecules (157-159). Under inflammatory conditions, when NET formation is induced, circulating tumor cells are more prone to adhere to end organ vasculature (158-160). Thus, given that the entrapment of bacteria is one of the primary roles attributed to NETs, they probably act accordingly to capture circulating tumor cells. By entrapping tumor cells and exposing them to various neutrophil-derived factors, NETs may generate a microenvironment rich in proteins and enzymes that promote tumor cell survival and progression $(35,36,149,153)$. Taken together, these data support a potential pro-metastatic role for NETs, involved in early adhesion, proliferation, invasion, and angiogenesis.
Neutrophil extracellular traps have also been implicated in cancer-associated thrombosis, the second most common cause of death in cancer patients (34). Recently, it was demonstrated that, through the generation of NETs, neutrophils provide a scaffold and a stimulus for platelet adhesion and thrombus formation (75). NETs were shown to promote coagulation as well $(68,75)$. Moreover, a recent study based on murine models reported that both leukemia and solid tumors produce a factor, G-CSF, that primes neutrophils to undergo NETosis and predisposes the host to thrombosis (34). In conclusion, NETs have been identified as a key player in cancer-associated thrombosis.

The biological significance of NETs in cancer remains unclear. It is hypothesized that initially they represent a reaction of the tumor environment against the growing cancer. However, NETs seem to play an adverse role in tumor growth, offering a scaffold with an array of biologically active molecules attached on it, which may promote malignant cell survival, growth, and local tumor expansion.

\section{THERAPEUTIC AND DIAGNOSTIC/ PROGNOSTIC POTENTIAL OF NETS}

To date, clinical and experimental evidence highlight the significant role of NETs in the pathophysiology of the aforementioned diseases. Even though studies in animal models have shown the beneficial role of NET inhibition, especially in thrombosis, it is yet unknown whether NET-targeting therapies could be effective in clinic (161). NET induction or inhibition could be beneficial for patients with diseases that have been associated with restricted or excessive NET formation, respectively (Table 1). To this end, drug repositioning offers the opportunity for the immediate use of therapeutic agents that induce or inhibit NETs, which are already used in clinic (11).

Several drugs already used in clinical practice might affect either NET formation or integrity, or the expression of NET proteins. For instance, it is known that hydroxychloroquine (HCQ), a drug that has been used for decades in the treatment of SLE, has anti-autophagic effect (162). Since the autophagic machinery is an essential step for NETosis, the effectiveness of HCQ may be mediated through the indirect inhibition of NET formation (Table 1; Figure 3A). In addition, rhDNase administration, a therapy used in patients with CF aiming to the liquefaction of mucus (142), may possibly target NET structures. DNase promotes thrombolysis via degradation of NETs in murine models (Table 1; Figure 3B) $(64,76)$. Moreover, monoclonal antibodies are widely used against bioactive NET proteins, externalized through NET formation. In psoriasis, treatment with anti-IL-17 antibodies (121), probably targets the IL-17-decorated NETs, the main origin of bioactive IL-17 in psoriasis (66). Finally, NET-bound IL- $1 \beta$ may be one of the targets of anti-IL-1 $\beta$ therapies, such as canakinumab which targets bioactive IL-1 $\beta$ in FMF or gout patients (Table 1; Figure 3C) (134).

There are a few recent studies demonstrating that NETs could also have prognostic and/or diagnostic potential, as they could represent a disease activity marker for some of the aforementioned 
TABLE 1 | Potential and applied therapeutic strategies targeting neutrophil extracellular traps (NETs).

\begin{tabular}{|c|c|c|c|c|c|}
\hline \multicolumn{2}{|c|}{ NET formation blockade } & \multicolumn{2}{|c|}{ NET integrity dismantling } & \multicolumn{2}{|c|}{ NET components antagonism } \\
\hline Drug (activity) & Disorder (species) & Drug (activity) & Disorder (species) & Drug (activity) & $\begin{array}{l}\text { Disorder } \\
\text { (species) }\end{array}$ \\
\hline $\begin{array}{l}\text { Hydroxychloroquine (autophagy } \\
\text { inhibition) }\end{array}$ & SLE (h) (162) & $\begin{array}{l}\text { DNases (DNA } \\
\text { dismantling) }\end{array}$ & $\begin{array}{l}\text { Thrombosis, cystic } \\
\text { fibrosis }(h)(64,76,142)\end{array}$ & $\begin{array}{l}\text { Secukinumab (IL-17 } \\
\text { inhibition) }\end{array}$ & $\begin{array}{l}\text { Psoriasis }(h) \\
(121)\end{array}$ \\
\hline $\begin{array}{l}\mathrm{N} \text {-acetylcysteine (ROS } \\
\text { reduction) }\end{array}$ & SLE $(h)(163)$ & $\begin{array}{l}\text { Heparin } \\
\text { (chromatin } \\
\text { dismantling) }\end{array}$ & Thrombosis $(h)(75)$ & 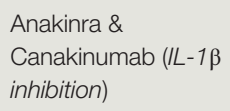 & $\begin{array}{l}\text { FMF, gout }(h) \\
(23,24,134)\end{array}$ \\
\hline Sifalimumab (IFN- $\alpha$ inhibition) & SLE $(h)(164)$ & & & & \\
\hline $\begin{array}{l}\text { Cl-Amidine (PAD family } \\
\text { inhibition) }\end{array}$ & RA, SLE $(m)(165,166)$ & & & & \\
\hline GSK199 (PAD4 inhibition) & $(m)(167)$ & & & & \\
\hline Adalimumab (TNF inhibition) & RA, psoriasis $(h)(115,168)$ & & & & \\
\hline $\begin{array}{l}\text { Roflumilast (neutrophil-platelet } \\
\text { interaction inhibition) }\end{array}$ & Thrombosis $(h)(169)$ & & & & \\
\hline Eculizumab (C5a inhibition) & $\mathrm{PNH}(h)(170)$ & & & & \\
\hline
\end{tabular}

FMF, familial Mediterranean fever; $h$, human model; IFN- $\alpha$, interferon alpha; IL-17, interleukin 17; IL-1 $\beta$, interleukin 1 beta; m, murine model; PAD4, peptidyl arginine deiminase type N; PNH, paroxysmal nocturnal hemoglobinuria; RA, rheumatoid arthritis; ROS, reactive oxygen species; SLE, systemic lupus erythematosus; TNF, tumor necrosis factor.

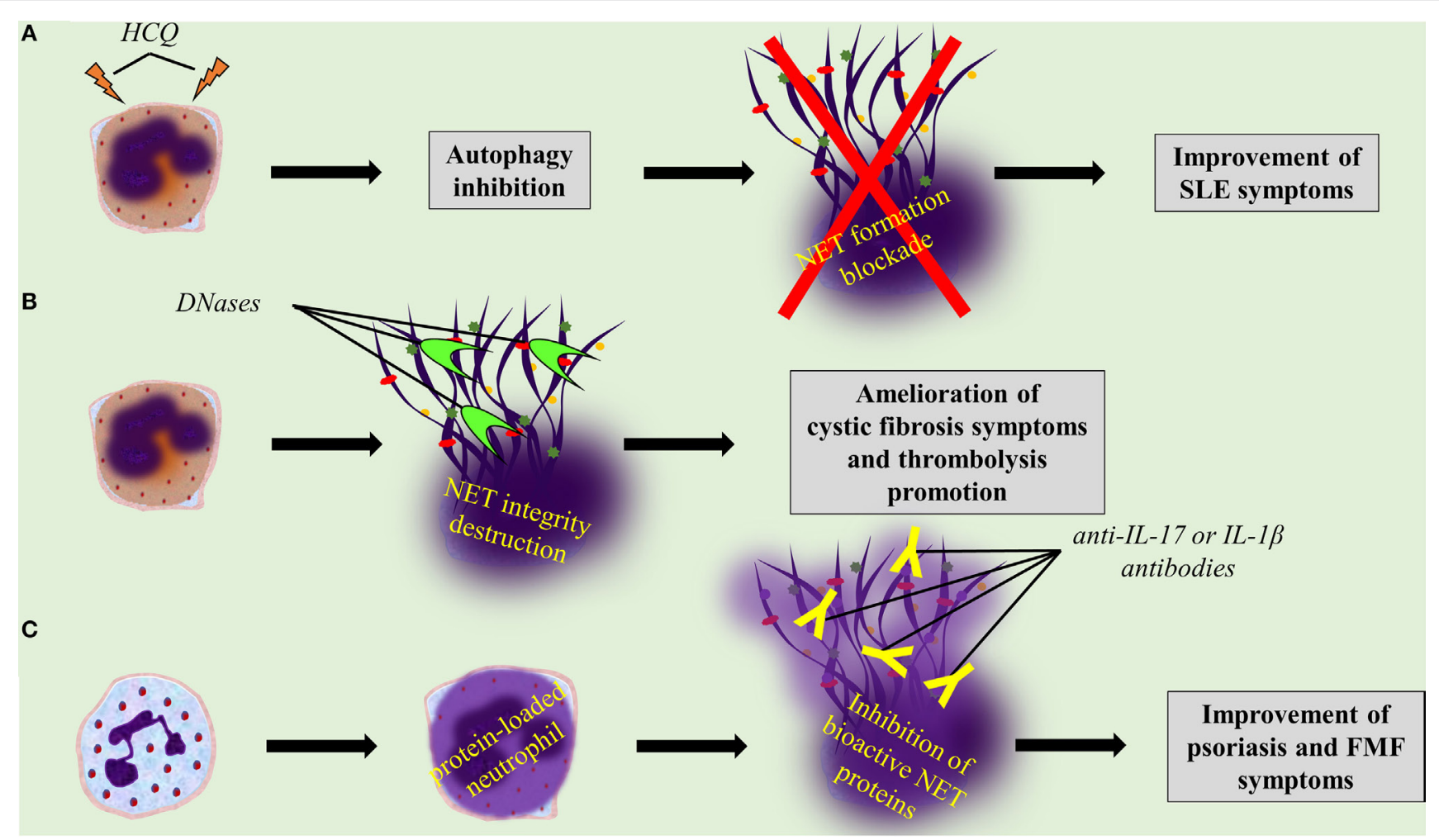

FIGURE 3 | Targeting neutrophil extracellular trap (NET) formation or integrity, or specific NET proteins, promises novel therapeutic strategies. (A) Hydroxychloroquine inhibits NET formation through its anti-autophagic activity. (B) rhDNase and DNase I dismantle NET structures. (C) Anti-interleukin 17 (IL-17) and anti-interleukin 1 beta (IL-1 $\beta$ ) antibodies blockade bioactive IL-17 and IL-1 $\beta$ on NETs, respectively.

diseases (161). Furthermore, the measurement of NET release or specific NET protein expression in blood samples and biopsies could be a useful diagnostic tool $(150,171)$. Nevertheless, further experimental data are needed to evaluate the therapeutic, prognostic, and/or diagnostic potential of NETs.

\section{CONCLUSION}

The identification of NETs and the characterization of their role in disease have revived the overlooked role of neutrophils in disease pathogenesis. Phagocytosis of pathogens and limitation 
of infection was considered the exclusive role of neutrophils. However, mechanistic studies in animal models and clinical observation dramatically altered our perception of the involvement of neutrophils in disease during the last decade. From a patrolling police force, neutrophils are considered nowadays an important player in autoimmune diseases or thrombotic disorders, which were previously thought to be exclusively mediated by adaptive immune system and platelet or endothelial cells, respectively. The characterization of the differential protein load and function of neutrophils, and subsequently of NETs, in distinct disorders can provide novel diagnostic targets and targets for therapeutic intervention. Additionally, the study on the role of NETs in modulation of tissue homeostasis, including the initiation and resolution of inflammation and the elucidation of the effect of NETs on different cell population involved in inflammatory, autoimmune, or thrombotic disorders, will increase our

\section{REFERENCES}

1. Fuchs TA, Abed U, Goosmann C, Hurwitz R, Schulze I, Wahn V, et al. Novel cell death program leads to neutrophil extracellular traps. J Cell Biol (2007) 176(2):231-41. doi:10.1083/jcb.200606027

2. Papayannopoulos V, Zychlinsky A. NETs: a new strategy for using old weapons. Trends Immunol (2009) 30(11):513-21. doi:10.1016/j.it.2009. 07.011

3. Nauseef WM, Borregaard N. Neutrophils at work. Nat Immunol (2014) 15(7):602-11. doi:10.1038/ni.2921

4. Mitroulis I, Alexaki VI, Kourtzelis I, Ziogas A, Hajishengallis G, Chavakis T. Leukocyte integrins: role in leukocyte recruitment and as therapeutic targets in inflammatory disease. Pharmacol Ther (2015) 147:123-35. doi:10.1016/ j.pharmthera.2014.11.008

5. Boettcher S, Manz MG. Sensing and translation of pathogen signals into demand-adapted myelopoiesis. Curr Opin Hematol (2016) 23(1):5-10. doi:10.1097/MOH.0000000000000201

6. Brinkmann V, Reichard U, Goosmann C, Fauler B, Uhlemann Y, Weiss DS, et al. Neutrophil extracellular traps kill bacteria. Science (2004) 303(5663):1532-5. doi:10.1126/science. 1092385

7. Remijsen Q, Kuijpers TW, Wirawan E, Lippens S, Vandenabeele P, Vanden Berghe T. Dying for a cause: NETosis, mechanisms behind an antimicrobial cell death modality. Cell Death Differ (2011) 18(4):581-8. doi:10.1038/ cdd.2011.1

8. Beiter K, Wartha F, Albiger B, Normark S, Zychlinsky A, Henriques-Normark B. An endonuclease allows Streptococcus pneumoniae to escape from neutrophil extracellular traps. Curr Biol (2006) 16(4):401-7. doi:10.1016/ j.cub.2006.01.056

9. Ramos-Kichik V, Mondragón-Flores R, Mondragón-Castelán M, GonzalezPozos S, Muñiz-Hernandez S, Rojas-Espinosa O, et al. Neutrophil extracellular traps are induced by Mycobacterium tuberculosis. Tuberculosis (Edinb) (2009) 89(1):29-37. doi:10.1016/j.tube.2008.09.009

10. Urban CF, Reichard U, Brinkmann V, Zychlinsky A. Neutrophil extracellular traps capture and kill Candida albicans yeast and hyphal forms. Cell Microbiol (2006) 8(4):668-76. doi:10.1111/j.1462-5822.2005.00659.x

11. Konstantinidis T, Kambas K, Mitsios A, Panopoulou M, Tsironidou $\mathrm{V}$, Dellaporta E, et al. Immunomodulatory role of clarithromycin in Acinetobacter baumannii infection via formation of neutrophil extracellular traps. Antimicrob Agents Chemother (2016) 60(2):1040-8. doi:10.1128/ AAC.02063-15

12. Kambas K, Mitroulis I, Apostolidou E, Girod A, Chrysanthopoulou A, Pneumatikos I, et al. Autophagy mediates the delivery of thrombogenic tissue factor to neutrophil extracellular traps in human sepsis. PLoS One (2012) 7(9):e45427. doi:10.1371/journal.pone.0045427

13. Kambas K, Mitroulis I, Ritis K. The emerging role of neutrophils in thrombosis-the journey of TF through NETs. Front Immunol (2012) 3:385. doi:10.3389/fimmu.2012.00385 knowledge in the mechanisms that govern the pathogenesis of complex disorders. The clarification of the role of NETs in the pathogenesis of such disorders and the clinical use of therapeutic agents that target NETs will enable the identification of a group of disorders that could be characterized by the term NET-associated diseases or NETopathies.

\section{AUTHOR CONTRIBUTIONS}

AM, AA, SA, IM, and KR wrote the manuscript and created the figures. IM and $\mathrm{KR}$ also revised the manuscript.

\section{FUNDING}

This study was supported by the Scientific Committee of Democritus University of Thrace. Grant number - 80895 .

14. Kambas K, Chrysanthopoulou A, Vassilopoulos D, Apostolidou E, Skendros $\mathrm{P}$, Girod A, et al. Tissue factor expression in neutrophil extracellular traps and neutrophil derived microparticles in antineutrophil cytoplasmic antibody associated vasculitis may promote thromboinflammation and the thrombophilic state associated with the disease. Ann Rheum Dis (2014) 73(10):1854-63. doi:10.1136/annrheumdis-2013-203430

15. de Boer OJ, Li X, Teeling P, Mackaay C, Ploegmakers HJ, van der Loos CM, et al. Neutrophils, neutrophil extracellular traps and interleukin-17 associate with the organisation of thrombi in acute myocardial infarction. Thromb Haemost (2013) 109(2):290-7. doi:10.1160/TH12-06-0425

16. Stakos DA, Kambas K, Konstantinidis T, Mitroulis I, Apostolidou E, Arelaki $\mathrm{S}$, et al. Expression of functional tissue factor by neutrophil extracellular traps in culprit artery of acute myocardial infarction. Eur Heart J (2015) 36(22):1405-14. doi:10.1093/eurheartj/ehv007

17. Hakkim A, Fürnrohr BG, Amann K, Laube B, Abed UA, Brinkmann V, et al. Impairment of neutrophil extracellular trap degradation is associated with lupus nephritis. Proc Natl Acad Sci U S A (2010) 107(21):9813-8. doi:10.1073/ pnas.0909927107

18. Lande R, Ganguly D, Facchinetti V, Frasca L, Conrad C, Gregorio J, et al. Neutrophils activate plasmacytoid dendritic cells by releasing self-DNA-peptide complexes in systemic lupus erythematosus. Sci Transl Med (2011) 3(73):73ra19. doi:10.1126/scitranslmed.3001180

19. Kahlenberg JM, Kaplan MJ. Little peptide, big effects: the role of LL-37 in inflammation and autoimmune disease. J Immunol (2013) 191(10):4895-901. doi:10.4049/jimmunol.1302005

20. Leffler J, Martin M, Gullstrand B, Tydén H, Lood C, Truedsson L, et al. Neutrophil extracellular traps that are not degraded in systemic lupus erythematosus activate complement exacerbating the disease. J Immunol (2012) 188(7):3522-31. doi:10.4049/jimmunol.1102404

21. Couser WG, Johnson RJ. What is myeloperoxidase doing in ANCAassociated glomerulonephritis? Kidney Int (2015) 88(5):938-40. doi:10.1038/ ki.2015.259

22. Söderberg D, Kurz T, Motamedi A, Hellmark T, Eriksson P, Segelmark M. Increased levels of neutrophil extracellular trap remnants in the circulation of patients with small vessel vasculitis, but an inverse correlation to anti-neutrophil cytoplasmic antibodies during remission. Rheumatology (Oxford) (2015) 54(11):2085-94. doi:10.1093/rheumatology/kev217

23. Apostolidou E, Skendros P, Kambas K, Mitroulis I, Konstantinidis T, Chrysanthopoulou A, et al. Neutrophil extracellular traps regulate IL-1 $\beta$ mediated inflammation in familial Mediterranean fever. Ann Rheum Dis (2016) 75(1):269-77. doi:10.1136/annrheumdis-2014-205958

24. Mitroulis I, Kambas K, Chrysanthopoulou A, Skendros P, Apostolidou E, Kourtzelis I, et al. Neutrophil extracellular trap formation is associated with IL-1 $\beta$ and autophagy-related signaling in gout. PLoS One (2011) 6(12):e29318. doi:10.1371/journal.pone.0029318

25. Bennike TB, Carlsen TG, Ellingsen T, Bonderup OK, Glerup H, Bøgsted M, et al. Neutrophil extracellular traps in ulcerative colitis: a proteome analysis 
of intestinal biopsies. Inflamm Bowel Dis (2015) 21(9):2052-67. doi:10.1097/ MIB.0000000000000460

26. He Z, Si Y, Jiang T, Ma R, Zhang Y, Cao M, et al. Phosphotidylserine exposure and neutrophil extracellular traps enhance procoagulant activity in patients with inflammatory bowel disease. Thromb Haemost (2016) 115(4):738-51. doi:10.1160/TH15-09-0710

27. Menegazzo L, Ciciliot S, Poncina N, Mazzucato M, Persano M, Bonora B, et al. NETosis is induced by high glucose and associated with type 2 diabetes. Acta Diabetol (2015) 52(3):497-503. doi:10.1007/s00592-014-0676-x

28. Wang Y, Xiao Y, Zhong L, Ye D, Zhang J, Tu Y, et al. Increased neutrophil elastase and proteinase 3 and augmented NETosis are closely associated with $\beta$-cell autoimmunity in patients with type 1 diabetes. Diabetes (2014) 63(12):4239-48. doi:10.2337/db14-0480

29. Cheng OZ, Palaniyar N. NET balancing: a problem in inflammatory lung diseases. Front Immunol (2013) 4:1. doi:10.3389/fimmu.2013.00001

30. Grabcanovic-Musija F, Obermayer A, Stoiber W, Krautgartner W-D, Steinbacher P, Winterberg N, et al. Neutrophil extracellular trap (NET) formation characterises stable and exacerbated COPD and correlates with airflow limitation. Respir Res (2015) 16:59. doi:10.1186/s12931-015-0221-7

31. Marcos V, Zhou-Suckow Z, Önder Yildirim A, Bohla A, Hector A, Vitkov L, et al. Free DNA in cystic fibrosis airway fluids correlates with airflow obstruction. Mediators Inflamm (2015) 2015:408935. doi:10.1155/2015/408935

32. Dwyer M, Shan Q, D’Ortona S, Maurer R, Mitchell R, Olesen H, et al. Cystic fibrosis sputum DNA has NETosis characteristics and neutrophil extracellular trap release is regulated by macrophage migration-inhibitory factor. J Innate Immun (2014) 6(6):765-79. doi:10.1159/000363242

33. Chrysanthopoulou A, Mitroulis I, Apostolidou E, Arelaki S, Mikroulis D, Konstantinidis T, et al. Neutrophil extracellular traps promote differentiation and function of fibroblasts. J Pathol (2014) 233(3):294-307. doi:10.1002/ path. 4359

34. Demers M, Krause DS, Schatzberg D, Martinod K, Voorhees JR, Fuchs TA, et al. Cancers predispose neutrophils to release extracellular DNA traps that contribute to cancer-associated thrombosis. Proc Natl Acad Sci U S A (2012) 109(32):13076-81. doi:10.1073/pnas.1200419109

35. Cools-Lartigue J, Spicer J, McDonald B, Gowing S, Chow S, Giannias B, et al. Neutrophil extracellular traps sequester circulating tumor cells and promote metastasis. J Clin Invest (2013) 123(8):3446-58. doi:10.1172/JCI67484

36. Tohme S, Yazdani HO, Al-Khafaji AB, Chidi AP, Loughran P, Mowen K, et al. Neutrophil extracellular traps promote the development and progression of liver metastases after surgical stress. Cancer Res (2016) 76(6):1367-80. doi:10.1158/0008-5472.CAN-15-1591

37. Yang H, Biermann MH, Brauner JM, Liu Y, Zhao Y, Herrmann M. New insights into neutrophil extracellular traps: mechanisms of formation and role in inflammation. Front Immunol (2016) 7:302. doi:10.3389/fimmu.2016.00302

38. Lood C, Blanco LP, Purmalek MM, Carmona-Rivera C, De Ravin SS, Smith CK, et al. Neutrophil extracellular traps enriched in oxidized mitochondrial DNA are interferogenic and contribute to lupus-like disease. Nat Med (2016) 22(2):146-53. doi:10.1038/nm.4027

39. Yousefi S, Mihalache C, Kozlowski E, Schmid I, Simon HU. Viable neutrophils release mitochondrial DNA to form neutrophil extracellular traps. Cell Death Differ (2009) 16(11):1438-44. doi:10.1038/cdd.2009.96

40. Steinberg BE, Grinstein S. Unconventional roles of the NADPH oxidase: signaling, ion homeostasis, and cell death. Sci STKE (2007) 2007(379):e11. doi:10.1126/stke.3792007pe11

41. Yipp BG, Petri B, Salina D, Jenne CN, Scott BNV, Zbytnuik LD, et al. Infection-induced NETosis is a dynamic process involving neutrophil multitasking in vivo. Nat Med (2012) 18(9):1386-93. doi:10.1038/ nm. 2847

42. Yipp BG, Kubes P. NETosis: how vital is it? Blood (2013) 122(16):2784-94. doi:10.1182/blood-2013-04-457671

43. Wang Y, Li M, Stadler S, Correll S, Li P, Wang D, et al. Histone hypercitrullination mediates chromatin decondensation and neutrophil extracellular trap formation. J Cell Biol (2009) 184(2):205-13. doi:10.1083/jcb.200806072

44. Papayannopoulos V, Metzler KD, Hakkim A, Zychlinsky A. Neutrophil elastase and myeloperoxidase regulate the formation of neutrophil extracellular traps. J Cell Biol (2010) 191(3):677-91. doi:10.1083/jcb.201006052

45. Brinkmann V, Goosmann C, Kühn LI, Zychlinsky A. Automatic quantification of in vitro NET formation. Front Immunol (2013) 3:413. doi:10.3389/ fimmu.2012.00413
46. Zawrotniak M, Rapala-Kozik M. Neutrophil extracellular traps (NETs) formation and implications. Acta Biochim Pol (2013) 60(3):277-84.

47. Kolaczkowska E, Jenne CN, Surewaard BGJ, Thanabalasuriar A, Lee W-Y, Sanz M-J, et al. Molecular mechanisms of NET formation and degradation revealed by intravital imaging in the liver vasculature. Nat Commun (2015) 6:6673. doi: $10.1038 /$ ncomms7673

48. Kusunoki Y, Nakazawa D, Shida H, Hattanda F, Miyoshi A, Masuda S, et al. Peptidylarginine deiminase inhibitor suppresses neutrophil extracellular trap formation and MPO-ANCA production. Front Immunol (2016) 7:227. doi:10.3389/fimmu.2016.00227

49. Li P, Li M, Lindberg MR, Kennett MJ, Xiong N, Wang Y. PAD4 is essential for antibacterial innate immunity mediated by neutrophil extracellular traps. J Exp Med (2010) 207(9):1853-62. doi:10.1084/jem.20100239

50. Nauseef WM, Kubes P. Pondering neutrophil extracellular traps with healthy skepticism. Cell Microbiol (2016) 18(10):1349-57. doi:10.1111/ cmi. 12652

51. O'Neill LAJ, Kishton RJ, Rathmell J. A guide to immunometabolism for immunologists. Nat Rev Immunol (2016) 16(9):553-65. doi:10.1038/ nri.2016.70

52. Fossati G, Moulding DA, Spiller DG, Moots RJ, White MRH, Edwards SW. The mitochondrial network of human neutrophils: role in chemotaxis, phagocytosis, respiratory burst activation, and commitment to apoptosis. J Immunol (2003) 170(4):1964-72. doi:10.4049/jimmunol.170. 4.1964

53. Rodríguez-Espinosa O, Rojas-Espinosa O, Moreno-Altamirano MMB, López-Villegas EO, Sánchez-García FJ. Metabolic requirements for neutrophil extracellular traps formation. Immunology (2015) 145(2):213-24. doi:10.1111/imm.12437

54. Azevedo EP, Rochael NC, Guimarães-Costa AB, de Souza-Vieira TS, Ganilho J, Saraiva EM, et al. A metabolic shift toward pentose phosphate pathway is necessary for amyloid fibril- and phorbol 12-myristate 13-acetateinduced neutrophil extracellular trap (NET) formation. J Biol Chem (2015) 290(36):22174-83. doi:10.1074/jbc.M115.640094

55. Douda DN, Khan MA, Grasemann H, Palaniyar N. SK3 channel and mitochondrial ROS mediate NADPH oxidase-independent NETosis induced by calcium influx. Proc Natl Acad Sci U S A (2015) 112(9):2817-22. doi:10.1073/ pnas. 1414055112

56. Remijsen Q, Vanden Berghe T, Wirawan E, Asselbergh B, Parthoens E, De Rycke R, et al. Neutrophil extracellular trap cell death requires both autophagy and superoxide generation. Cell Res (2011) 21(2):290-304. doi:10.1038/ cr.2010.150

57. Eisenberg-Lerner A, Bialik S, Simon H-U, Kimchi A. Life and death partners: apoptosis, autophagy and the cross-talk between them. Cell Death Differ (2009) 16(7):966-75. doi:10.1038/cdd.2009.33

58. Cuervo AM. Autophagy: many paths to the same end. Mol Cell Biochem (2004) 263(1-2):55-72. doi:10.1023/B:MCBI.0000041848.57020.57

59. Itakura A, McCarty OJT. Pivotal role for the mTOR pathway in the formation of neutrophil extracellular traps via regulation of autophagy. Am J Physiol Cell Physiol (2013) 305(3):C348-54. doi:10.1152/ajpcell.00108.2013

60. Sha L-L, Wang H, Wang C, Peng H-Y, Chen M, Zhao M-H. Autophagy is induced by anti-neutrophil cytoplasmic Abs and promotes neutrophil extracellular traps formation. Innate Immun (2016) 22(8):658-65. doi:10.1177/1753425916668981

61. Tang S, Zhang Y, Yin S-W, Gao X-J, Shi W-W, Wang Y, et al. Neutrophil extracellular trap formation is associated with autophagy-related signalling in ANCA-associated vasculitis. Clin Exp Immunol (2015) 180(3):408-18. doi:10.1111/cei.12589

62. Maugeri N, Campana L, Gavina M, Covino C, De Metrio M, Panciroli C, et al. Activated platelets present high mobility group box 1 to neutrophils, inducing autophagy and promoting the extrusion of neutrophil extracellular traps. J Thromb Haemost (2014) 12(12):2074-88. doi:10.1111/ jth. 12710

63. Ramirez GA, Manfredi AA, Rovere-Querini P, Maugeri N. Bet on NETs! Or on how to translate basic science into clinical practice. Front Immunol (2016) 7:417. doi:10.3389/fimmu.2016.00417

64. von Brühl M-L, Stark K, Steinhart A, Chandraratne S, Konrad I, Lorenz M, et al. Monocytes, neutrophils, and platelets cooperate to initiate and propagate venous thrombosis in mice in vivo. J Exp Med (2012) 209(4):819-35. doi:10.1084/jem.20112322 
65. Kimball AS, Obi AT, Diaz JA, Henke PK. The emerging role of NETs in venous thrombosis and immunothrombosis. Front Immunol (2016) 7:236. doi:10.3389/fimmu.2016.00236

66. Lin AM, Rubin CJ, Khandpur R, Wang JY, Riblett M, Yalavarthi S, et al. Mast cells and neutrophils release IL-17 through extracellular trap formation in psoriasis. JImmunol (2011) 187(1):490-500. doi:10.4049/jimmunol. 1100123

67. Reyes-Castillo Z, Palafox-Sánchez CA, Parra-Rojas I, Martínez-Bonilla GE, del Toro-Arreola S, Ramírez-Dueñas MG, et al. Comparative analysis of autoantibodies targeting peptidylarginine deiminase type 4, mutated citrullinated vimentin and cyclic citrullinated peptides in rheumatoid arthritis: associations with cytokine profiles, clinical and genetic features. Clin Exp Immunol (2015) 182(2):119-31. doi:10.1111/cei.12677

68. Massberg S, Grahl L, von Bruehl M-L, Manukyan D, Pfeiler S, Goosmann C, et al. Reciprocal coupling of coagulation and innate immunity via neutrophil serine proteases. Nat Med (2010) 16(8):887-96. doi:10.1038/ nm. 2184

69. Schauer C, Janko C, Munoz LE, Zhao Y, Kienhöfer D, Frey B, et al. Aggregated neutrophil extracellular traps limit inflammation by degrading cytokines and chemokines. Nat Med (2014) 20(5):511-7. doi:10.1038/nm.3547

70. Savchenko AS, Martinod K, Seidman MA, Wong SL, Borissoff JI, Piazza G, et al. Neutrophil extracellular traps form predominantly during the organizing stage of human venous thromboembolism development. J Thromb Haemost (2014) 12(6):860-70. doi:10.1111/jth.12571

71. Riegger J, Byrne RA, Joner M, Chandraratne S, Gershlick AH, Ten Berg JM, et al. Histopathological evaluation of thrombus in patients presenting with stent thrombosis. A multicenter European study: a report of the prevention of late stent thrombosis by an interdisciplinary global European effort consortium. Eur Heart J (2016) 37(19):1538-49. doi:10.1093/eurheartj/ehv419

72. Clark SR, Ma AC, Tavener SA, McDonald B, Goodarzi Z, Kelly MM, et al. Platelet TLR4 activates neutrophil extracellular traps to ensnare bacteria in septic blood. Nat Med (2007) 13(4):463-9. doi:10.1038/nm1565

73. Delabranche X, Stiel L, Severac F, Galoisy A-C, Mauvieux L, Zobairi F, et al. Evidence of NETosis in septic shock-induced disseminated intravascular coagulation. Shock (2016). doi:10.1097/SHK.0000000000000719

74. Yalavarthi S, Gould TJ, Rao AN, Mazza LF, Morris AE, Núñez-Álvarez C, et al. Release of neutrophil extracellular traps by neutrophils stimulated with antiphospholipid antibodies: a newly identified mechanism of thrombosis in the antiphospholipid syndrome. Arthritis Rheumatol (2015) 67(11):2990-3003. doi:10.1002/art.39247

75. Fuchs TA, Brill A, Duerschmied D, Schatzberg D, Monestier M, Myers DD, et al. Extracellular DNA traps promote thrombosis. Proc Natl Acad Sci U S A (2010) 107(36):15880-5. doi:10.1073/pnas.1005743107

76. Brill A, Fuchs TA, Savchenko AS, Thomas GM, Martinod K, De Meyer SF, et al. Neutrophil extracellular traps promote deep vein thrombosisinmice.J Thromb Haemost (2012) 10(1):136-44. doi:10.1111/j.1538-7836.2011.04544.x

77. Cedervall J, Zhang Y, Huang H, Zhang L, Femel J, Dimberg A, et al. Neutrophil extracellular traps accumulate in peripheral blood vessels and compromise organ function in tumor-bearing animals. Cancer Res (2015) 75(13):2653-62. doi:10.1158/0008-5472.CAN-14-3299

78. Nakazawa D, Tomaru U, Yamamoto C, Jodo S, Ishizu A. Abundant neutrophil extracellular traps in thrombus of patient with microscopic polyangiitis. Front Immunol (2012) 3:333. doi:10.3389/fimmu.2012.00333

79. van Montfoort ML, Stephan F, Lauw MN, Hutten BA, Van Mierlo GJ, Solati S, et al. Circulating nucleosomes and neutrophil activation as risk factors for deep vein thrombosis. Arterioscler Thromb Vasc Biol (2013) 33(1):147-51. doi:10.1161/ATVBAHA.112.300498

80. Diaz JA, Fuchs TA, Jackson TO, Kremer Hovinga JA, Lämmle B, Henke PK, et al. Plasma DNA is elevated in patients with deep vein thrombosis. J Vasc Surg Venous Lymphat Disord (2013) 1(4):341-8.e1. doi:10.1016/j.jvsv.2012. 12.002

81. van Bijnen STA, Wouters D, van Mierlo GJ, Muus P, Zeerleder S. Neutrophil activation and nucleosomes as markers of systemic inflammation in paroxysmal nocturnal hemoglobinuria: effects of eculizumab. J Thromb Haemost (2015) 13(11):2004-11. doi:10.1111/jth.13125

82. Fuchs TA, Kremer Hovinga JA, Schatzberg D, Wagner DD, Lämmle B. Circulating DNA and myeloperoxidase indicate disease activity in patients with thrombotic microangiopathies. Blood (2012) 120(6):1157-64. doi:10.1182/blood-2012-02-412197
83. Lakbakbi S, Debrumetz A, Terryn C, Szymezak J, Rieu P, Nguyen P. Tissue factor expressed by adherent cells contributes to hemodialysismembrane thrombogenicity. Thromb Res (2016) 144:218-23. doi:10.1016/j. thromres.2016.05.017

84. Stark K, Philippi V, Stockhausen S, Busse J, Antonelli A, Miller M, et al. Disulfide HMGB1 derived from platelets coordinates venous thrombosis in mice. Blood (2016) 128(20):2435-49. doi:10.1182/blood-2016-04-710632

85. Martinod K, Demers M, Fuchs TA, Wong SL, Brill A, Gallant M, et al. Neutrophil histone modification by peptidylarginine deiminase 4 is critical for deep vein thrombosis in mice. Proc Natl Acad Sci U S A (2013) 110(21):8674-9. doi:10.1073/pnas.1301059110

86. Meng H, Yalavarthi S, Kanthi Y, Mazza LF, Elfline MA, Luke CE, et al. In vivo role of neutrophil extracellular traps in antiphospholipid antibody-mediated venous thrombosis. Arthritis Rheumatol (2016). doi:10.1002/art.39938

87. Rapaport SI, Rao LV. The tissue factor pathway: how it has become a "prima ballerina". Thromb Haemost (1995) 74(1):7-17.

88. Slaba I, Wang J, Kolaczkowska E, McDonald B, Lee W-Y, Kubes P. Imaging the dynamic platelet-neutrophil response in sterile liver injury and repair in mice. Hepatology (2015) 62(5):1593-605. doi:10.1002/hep.28003

89. Tsokos GC. Systemic lupus erythematosus. N Engl JMed (2011) 365(22):2110-21. doi:10.1056/NEJMra1100359

90. Knight JS, Carmona-Rivera C, Kaplan MJ. Proteins derived from neutrophil extracellular traps may serve as self-antigens and mediate organ damage in autoimmune diseases. Front Immunol (2012) 3:380. doi:10.3389/ fimmu.2012.00380

91. Bosch X. Systemic lupus erythematosus and the neutrophil. N Engl J Med (2011) 365(8):758-60. doi:10.1056/NEJMcibr1107085

92. Smith CK, Kaplan MJ. The role of neutrophils in the pathogenesis of systemic lupus erythematosus. Curr Opin Rheumatol (2015) 27(5):448-53. doi:10.1097/BOR.0000000000000197

93. Villanueva E, Yalavarthi S, Berthier CC, Hodgin JB, Khandpur R, Lin AM, et al. Netting neutrophils induce endothelial damage, infiltrate tissues, and expose immunostimulatory molecules in systemic lupus erythematosus. J Immunol (2011) 187(1):538-52. doi:10.4049/jimmunol.1100450

94. Leffler J, Gullstrand B, Jönsen A, Nilsson J-Å, Martin M, Blom AM, et al. Degradation of neutrophil extracellular traps co-varies with disease activity in patients with systemic lupus erythematosus. Arthritis Res Ther (2013) 15(4):R84. doi:10.1186/ar4264

95. Smith CK, Vivekanandan-Giri A, Tang C, Knight JS, Mathew A, Padilla RL, et al. Neutrophil extracellular trap-derived enzymes oxidize high-density lipoprotein: an additional proatherogenic mechanism in systemic lupus erythematosus. Arthritis Rheumatol (2014) 66(9):2532-44. doi:10.1002/ art.38703

96. Dieker J, Tel J, Pieterse E, Thielen A, Rother N, Bakker M, et al. Circulating apoptotic microparticles in systemic lupus erythematosus patients drive the activation of dendritic cell subsets and prime neutrophils for NETosis. Arthritis Rheumatol (2016) 68(2):462-72. doi:10.1002/art.39417

97. Garcia-Romo GS, Caielli S, Vega B, Connolly J, Allantaz F, Xu Z, et al. Netting neutrophils are major inducers of type I IFN production in pediatric systemic lupus erythematosus. Sci Transl Med (2011) 3(73):73ra20. doi:10.1126/ scitranslmed.3001201

98. Carmona-Rivera C, Kaplan MJ. Detection of SLE antigens in neutrophil extracellular traps (NETs). Methods Mol Biol (2014) 1134:151-61. doi:10.1007/978-1-4939-0326-9_11

99. Pieterse E, Hofstra J, Berden J, Herrmann M, Dieker J, van der Vlag J. Acetylated histones contribute to the immunostimulatory potential of neutrophil extracellular traps in systemic lupus erythematosus. Clin Exp Immunol (2015) 179(1):68-74. doi:10.1111/cei.12359

100. Carmona-Rivera C, Zhao W, Yalavarthi S, Kaplan MJ. Neutrophil extracellular traps induce endothelial dysfunction in systemic lupus erythematosus through the activation of matrix metalloproteinase-2. Ann Rheum Dis (2015) 74(7):1417-24. doi:10.1136/annrheumdis-2013-204837

101. Yu Y, Su K. Neutrophil extracellular traps and systemic lupus erythematosus. J Clin Cell Immunol (2013) 4(4):139. doi:10.4172/2155-9899. 1000139

102. Lindau D, Mussard J, Rabsteyn A, Ribon M, Kötter I, Igney A, et al. TLR9 independent interferon $\alpha$ production by neutrophils on NETosis in response to circulating chromatin, a key lupus autoantigen. Ann Rheum Dis (2014) 73(12):2199-207. doi:10.1136/annrheumdis-2012-203041 
103. Chitrabamrung S, Rubin RL, Tan EM. Serum deoxyribonuclease I and clinical activity in systemic lupus erythematosus. Rheumatol Int (1981) 1(2):55-60. doi:10.1007/BF00541153

104. Yeh T-M, Chang H-C, Liang C-C, Wu J-J, Liu M-F. Deoxyribonucleaseinhibitory antibodies in systemic lupus erythematosus. J Biomed Sci (2003) 10(5):544-51. doi:10.1007/BF02256116

105. Chauhan SK, Rai R, Singh VV, Rai M, Rai G. Differential clearance mechanisms, neutrophil extracellular trap degradation and phagocytosis, are operative in systemic lupus erythematosus patients with distinct autoantibody specificities. Immunol Lett (2015) 168(2):254-9. doi:10.1016/ j.imlet.2015.09.016

106. Leffler J, Ciacma K, Gullstrand B, Bengtsson AA, Martin M, Blom AM. A subset of patients with systemic lupus erythematosus fails to degrade DNA from multiple clinically relevant sources. Arthritis Res Ther (2015) 17:205. doi:10.1186/s13075-015-0726-y

107. Kessenbrock K, Krumbholz M, Schönermarck U, Back W, Gross WL, Werb $Z$, et al. Netting neutrophils in autoimmune small-vessel vasculitis. Nat Med (2009) 15(6):623-5. doi:10.1038/nm.1959

108. O'Sullivan KM, Lo CY, Summers SA, Elgass KD, McMillan PJ, Longano A, et al. Renal participation of myeloperoxidase in antineutrophil cytoplasmic antibody (ANCA)-associated glomerulonephritis. Kidney Int (2015) 88(5):1030-46. doi:10.1038/ki.2015.202

109. Yoshida M, Sasaki M, Sugisaki K, Yamaguchi Y, Yamada M. Neutrophil extracellular trap components in fibrinoid necrosis of the kidney with myeloperoxidase-ANCA-associated vasculitis. Clin Kidney J (2013) 6(3):308-12. doi:10.1093/ckj/stt048

110. Grayson PC, Carmona-Rivera C, Xu L, Lim N, Gao Z, Asare AL, et al. Neutrophil-related gene expression and low-density granulocytes associated with disease activity and response to treatment in antineutrophil cytoplasmic antibody-associated vasculitis. Arthritis Rheumatol (2015) 67(7):1922-32. doi:10.1002/art.39153

111. Huang Y-M, Wang H, Wang C, Chen M, Zhao M-H. Promotion of hypercoagulability in antineutrophil cytoplasmic antibody-associated vasculitis by C5a-induced tissue factor-expressing microparticles and neutrophil extracellular traps. Arthritis Rheumatol (2015) 67(10):2780-90. doi:10.1002/ art.39239

112. Sangaletti S, Tripodo C, Chiodoni C, Guarnotta C, Cappetti B, Casalini P, et al. Neutrophil extracellular traps mediate transfer of cytoplasmic neutrophil antigens to myeloid dendritic cells toward ANCA induction and associated autoimmunity. Blood (2012) 120(15):3007-18. doi:10.1182/ blood-2012-03-416156

113. Wright HL, Moots RJ, Edwards SW. The multifactorial role of neutrophils in rheumatoid arthritis. Nat Rev Rheumatol (2014) 10(10):593-601. doi:10.1038/nrrheum.2014.80

114. Deane KD, Norris JM, Holers VM. Pre-clinical rheumatoid arthritis: identification, evaluation and future directions for investigation. Rheum Dis Clin North Am (2010) 36(2):213-41. doi:10.1016/j.rdc.2010.02.001

115. Khandpur R, Carmona-Rivera C, Vivekanandan-Giri A, Gizinski A, Yalavarthi S, Knight JS, et al. NETs are a source of citrullinated autoantigens and stimulate inflammatory responses in rheumatoid arthritis. Sci Transl Med (2013) 5(178):178ra40. doi:10.1126/scitranslmed.3005580

116. Zhao J, Zhao Y, He J, Jia R, Li Z. Prevalence and significance of antipeptidylarginine deiminase 4 antibodies in rheumatoid arthritis. J Rheumatol (2008) 35(6):969-74.

117. Spengler J, Lugonja B, Ytterberg AJ, Zubarev RA, Creese AJ, Pearson MJ, et al. Release of active peptidyl arginine deiminases by neutrophils can explain production of extracellular citrullinated autoantigens in rheumatoid arthritis synovial fluid. Arthritis Rheumatol (2015) 67(12):3135-45. doi:10.1002/ art. 39313

118. Nestle FO, Kaplan DH, Barker J. Psoriasis. N Engl J Med (2009) 361(5):496509. doi:10.1056/NEJMra0804595

119. Schön MP, Broekaert SMC, Erpenbeck L. Sexy again: the renaissance of neutrophils in psoriasis. Exp Dermatol (2016). doi:10.1111/exd.13067

120. Muhr P, Renne J, Schaefer V, Werfel T, Wittmann M. Primary human keratinocytes efficiently induce IL-1-dependent IL-17 in CCR6+ T cells. Exp Dermatol (2010) 19(12):1105-7. doi:10.1111/j.1600-0625.2010.01134.x

121. Hueber W, Patel DD, Dryja T, Wright AM, Koroleva I, Bruin G, et al. Effects of AIN457, a fully human antibody to interleukin-17A, on psoriasis, rheumatoid arthritis, and uveitis. Sci Transl Med (2010) 2(52):52ra72. doi:10.1126/ scitranslmed.3001107

122. Leonardi C, Matheson R, Zachariae C, Cameron G, Li L, Edson-Heredia E, et al. Anti-interleukin-17 monoclonal antibody ixekizumab in chronic plaque psoriasis. NEngl J Med (2012) 366(13):1190-9. doi:10.1056/NEJMoa1109997

123. Papp KA, Leonardi C, Menter A, Ortonne J-P, Krueger JG, Kricorian G, et al. Brodalumab, an anti-interleukin-17-receptor antibody for psoriasis. N Engl J Med (2012) 366(13):1181-9. doi:10.1056/NEJMoa1 109017

124. Keijsers RRMC, Hendriks AGM, van Erp PEJ, van Cranenbroek B, van de Kerkhof PCM, Koenen HJPM, et al. In vivo induction of cutaneous inflammation results in the accumulation of extracellular trap-forming neutrophils expressing ROR $\gamma \mathrm{t}$ and IL-17. JInvest Dermatol (2014) 134(5):1276-84. doi:10.1038/jid.2013.526

125. Leppkes M, Maueröder C, Hirth S, Nowecki S, Günther C, Billmeier U, et al. Externalized decondensed neutrophil chromatin occludes pancreatic ducts and drives pancreatitis. Nat Commun (2016) 7:10973. doi:10.1038/ ncomms 10973

126. Martin WJ, Walton M, Harper J. Resident macrophages initiating and driving inflammation in a monosodium urate monohydrate crystal-induced murine peritoneal model of acute gout. Arthritis Rheum (2009) 60(1):281-9. doi:10.1002/art.24185

127. Liu-Bryan R, Scott P, Sydlaske A, Rose DM, Terkeltaub R. Innate immunity conferred by Toll-like receptors 2 and 4 and myeloid differentiation factor 88 expression is pivotal to monosodium urate monohydrate crystal-induced inflammation. Arthritis Rheum (2005) 52(9):2936-46. doi:10.1002/art.21238

128. Scott P, Ma H, Viriyakosol S, Terkeltaub R, Liu-Bryan R. Engagement of CD14 mediates the inflammatory potential of monosodium urate crystals. J Immunol (2006) 177(9):6370-8. doi:10.4049/jimmunol.177.9.6370

129. Mitroulis I, Kambas K, Ritis K. Neutrophils, IL-1 $\beta$, and gout: is there a link? Semin Immunopathol (2013) 35(4):501-12. doi:10.1007/s00281-013-0361-0

130. Terkeltaub R. Update on gout: new therapeutic strategies and options. Nat Rev Rheumatol (2010) 6(1):30-8. doi:10.1038/nrrheum.2009.236

131. Schorn C, Janko C, Krenn V, Zhao Y, Munoz LE, Schett G, et al. Bonding the foe - NETting neutrophils immobilize the pro-inflammatory monosodium urate crystals. Front Immunol (2012) 3:376. doi:10.3389/fimmu.2012.00376

132. Maueröder C, Kienhöfer D, Hahn J, Schauer C, Manger B, Schett G, et al. How neutrophil extracellular traps orchestrate the local immune response in gout. J Mol Med (Berl) (2015) 93(7):727-34. doi:10.1007/s00109-015-1295-x

133. Mitroulis I, Skendros P, Ritis K. Targeting IL-1beta in disease; the expanding role of NLRP3 inflammasome. Eur J Intern Med (2010) 21(3):157-63. doi:10.1016/j.ejim.2010.03.005

134. Dinarello CA, van der Meer JWM. Treating inflammation by blocking interleukin-1 in humans. Semin Immunol (2013) 25(6):469-84. doi:10.1016/ j.smim.2013.10.008

135. Kahn SE, Cooper ME, Del Prato S. Pathophysiology and treatment of type 2 diabetes: perspectives on the past, present, and future. Lancet (2014) 383(9922):1068-83. doi:10.1016/S0140-6736(13)62154-6

136. Joshi MB, Lad A, Bharath Prasad AS, Balakrishnan A, Ramachandra L, Satyamoorthy K. High glucose modulates IL-6 mediated immune homeostasis through impeding neutrophil extracellular trap formation. FEBS Lett (2013) 587(14):2241-6. doi:10.1016/j.febslet.2013.05.053

137. Wong SL, Demers M, Martinod K, Gallant M, Wang Y, Goldfine AB, et al. Diabetes primes neutrophils to undergo NETosis, which impairs wound healing. Nat Med (2015) 21(7):815-9. doi:10.1038/nm.3887

138. Huang J, Xiao Y, Xu A, Zhou Z. Neutrophils in type 1 diabetes. J Diabetes Investig (2016) 7(5):652-63. doi:10.1111/jdi.12469

139. Qin J, Fu S, Speake C, Greenbaum CJ, Odegard JM. NETosis-associated serum biomarkers are reduced in type 1 diabetes in association with neutrophil count. Clin Exp Immunol (2016) 184(3):318-22. doi:10.1111/cei.12783

140. Roche N, Marthan R, Berger P, Chambellan A, Chanez P, Aguilaniu $\mathrm{B}$, et al. Beyond corticosteroids: future prospects in the management of inflammation in COPD. Eur Respir Rev (2011) 20(121):175-82. doi:10.1183/09059180.00004211

141. Papayannopoulos V, Staab D, Zychlinsky A. Neutrophil elastase enhances sputum solubilization in cystic fibrosis patients receiving DNase therapy. PLoS One (2011) 6(12):e28526. doi:10.1371/journal.pone.0028526

142. Milla CE. Recombinant human DNase in cystic fibrosis. Lancet (1999) 354(9176):428. doi:10.1016/S0140-6736(05)75848-7 
143. Pressler T. Review of recombinant human deoxyribonuclease (rhDNase) in the management of patients with cystic fibrosis. Biologics (2008) 2(4):611-7. doi:10.2147/BTT.S3052

144. Caudrillier A, Kessenbrock K, Gilliss BM, Nguyen JX, Marques MB, Monestier $\mathrm{M}$, et al. Platelets induce neutrophil extracellular traps in transfusion-related acute lung injury. J Clin Invest (2012) 122(7):2661-71. doi:10.1172/JCI61303

145. Dubois AV, Gauthier A, Bréa D, Varaigne F, Diot P, Gauthier F, et al. Influence of DNA on the activities and inhibition of neutrophil serine proteases in cystic fibrosis sputum. Am J Respir Cell Mol Biol (2012) 47(1):80-6. doi:10.1165/ rcmb.2011-0380OC

146. Berger-Achituv S, Brinkmann V, Abed UA, Kühn LI, Ben-Ezra J, Elhasid R, et al. A proposed role for neutrophil extracellular traps in cancer immunoediting. Front Immunol (2013) 4:48. doi:10.3389/fimmu.2013.00048

147. Demers M, Wagner DD. Neutrophil extracellular traps: a new link to cancer-associated thrombosis and potential implications for tumor progression. Oncoimmunology (2013) 2(2):e22946. doi:10.4161/onci.22946

148. Cools-Lartigue J, Spicer J, Najmeh S, Ferri L. Neutrophil extracellular traps in cancer progression. Cell Mol Life Sci (2014) 71(21):4179-94. doi:10.1007/ s00018-014-1683-3

149. Wculek SK, Malanchi I. Neutrophils support lung colonization of metastasis-initiating breast cancer cells. Nature (2015) 528(7582):413-7. doi:10.1038/ nature 16140

150. Arelaki S, Arampatzioglou A, Kambas K, Papagoras C, Miltiades P, Angelidou I, et al. Gradient infiltration of neutrophil extracellular traps in colon cancer and evidence for their involvement in tumour growth. PLoS One (2016) 11(5):e0154484. doi:10.1371/journal.pone.0154484

151. Ho-Tin-Noé B, Carbo C, Demers M, Cifuni SM, Goerge T, Wagner DD. Innate immune cells induce hemorrhage in tumors during thrombocytopenia. Am J Pathol (2009) 175(4):1699-708. doi:10.2353/ajpath.2009. 090460

152. Mishalian I, Bayuh R, Levy L, Zolotarov L, Michaeli J, Fridlender ZG. Tumorassociated neutrophils (TAN) develop pro-tumorigenic properties during tumor progression. Cancer Immunol Immunother (2013) 62(11):1745-56. doi:10.1007/s00262-013-1476-9

153. Sangaletti S, Tripodo C, Vitali C, Portararo P, Guarnotta C, Casalini P, et al. Defective stromal remodeling and neutrophil extracellular traps in lymphoid tissues favor the transition from autoimmunity to lymphoma. Cancer Discov (2014) 4(1):110-29. doi:10.1158/2159-8290.CD-13-0276

154. Narasaraju T, Yang E, Samy RP, Ng HH, Poh WP, Liew A-A, et al. Excessive neutrophils and neutrophil extracellular traps contribute to acute lung injury of influenza pneumonitis. Am J Pathol (2011) 179(1):199-210. doi:10.1016/ j.ajpath.2011.03.013

155. McDonald B, Urrutia R, Yipp BG, Jenne CN, Kubes P. Intravascular neutrophil extracellular traps capture bacteria from the bloodstream during sepsis. Cell Host Microbe (2012) 12(3):324-33. doi:10.1016/j.chom.2012.06.011

156. Meng W, Paunel-Görgülü A, Flohé S, Hoffmann A, Witte I, MacKenzie C, et al. Depletion of neutrophil extracellular traps in vivo results in hypersusceptibility to polymicrobial sepsis in mice. Crit Care (2012) 16(4):R137. doi:10.1186/cc11442

157. Hsu RYC, Chan CHF, Spicer JD, Rousseau MC, Giannias B, Rousseau S, et al. LPS-induced TLR4 signaling in human colorectal cancer cells increases betal integrin-mediated cell adhesion and liver metastasis. Cancer Res (2011) 71(5):1989-98. doi:10.1158/0008-5472.CAN-10-2833

158. McDonald B, Spicer J, Giannais B, Fallavollita L, Brodt P, Ferri LE. Systemic inflammation increases cancer cell adhesion to hepatic sinusoids by neutrophil mediated mechanisms. Int J Cancer (2009) 125(6):1298-305. doi:10.1002/ijc.24409

159. Spicer JD, McDonald B, Cools-Lartigue JJ, Chow SC, Giannias B, Kubes $\mathrm{P}$, et al. Neutrophils promote liver metastasis via Mac-1-mediated interactions with circulating tumor cells. Cancer Res (2012) 72(16):3919-27. doi:10.1158/0008-5472.CAN-11-2393

160. Liang S, Hoskins M, Khanna P, Kunz RF, Dong C. Effects of the tumor-leukocyte microenvironment on melanoma-neutrophil adhesion to the endothelium in a shear flow. Cell Mol Bioeng (2008) 1(2-3):189-200. doi:10.1007/s12195-008-0016-8

161. Barnado A, Crofford LJ, Oates JC. At the bedside: neutrophil extracellular traps (NETs) as targets for biomarkers and therapies in autoimmune diseases. J Leukoc Biol (2016) 99(2):265-78. doi:10.1189/jlb.5BT0615-234R

162. Costedoat-Chalumeau N, Dunogué B, Morel N, Le Guern V, Guettrot-Imbert G. Hydroxychloroquine: a multifaceted treatment in lupus. Presse Med (2014) 43(6 Pt 2):e167-80. doi:10.1016/j.lpm.2014.03.007

163. Garcia RJ, Francis L, Dawood M, Lai Z, Faraone SV, Perl A. Attention deficit and hyperactivity disorder scores are elevated and respond to $\mathrm{N}$-acetylcysteine treatment in patients with systemic lupus erythematosus. Arthritis Rheum (2013) 65(5):1313-8. doi:10.1002/art.37893

164. Khamashta M, Merrill JT, Werth VP, Furie R, Kalunian K, Illei GG, et al. Sifalimumab, an anti-interferon- $\alpha$ monoclonal antibody, in moderate to severe systemic lupus erythematosus: a randomised, double-blind, placebo-controlled study. Ann Rheum Dis (2016) 75(11):1909-16. doi:10.1136/ annrheumdis-2015-208562

165. Knight JS, Zhao W, Luo W, Subramanian V, O’Dell AA, Yalavarthi S, et al. Peptidylarginine deiminase inhibition is immunomodulatory and vasculoprotective in murine lupus. J Clin Invest (2013) 123(7):2981-93. doi:10.1172/ JCI67390

166. Willis VC, Gizinski AM, Banda NK, Causey CP, Knuckley B, Cordova $\mathrm{KN}$, et al. $\mathrm{N}$ - $\alpha$-benzoyl-N5-(2-chloro-1-iminoethyl)-L-ornithine amide, a protein arginine deiminase inhibitor, reduces the severity of murine collagen-induced arthritis. J Immunol (2011) 186(7):4396-404. doi:10.4049/ jimmunol.1001620

167. Lewis HD, Liddle J, Coote JE, Atkinson SJ, Barker MD, Bax BD, et al. Inhibition of PAD4 activity is sufficient to disrupt mouse and human NET formation. Nat Chem Biol (2015) 11(3):189-91. doi:10.1038/nchembio.1735

168. Patel T, Gordon KB. Adalimumab: efficacy and safety in psoriasis and rheumatoid arthritis. Dermatol Ther (2004) 17(5):427-31. doi:10.1111/j.1396-0296.2004.04045.x

169. Totani L, Amore C, Di Santo A, Dell'Elba G, Piccoli A, Martelli N, et al. Roflumilast inhibits leukocyte-platelet interactions and prevents the prothrombotic functions of polymorphonuclear leukocytes and monocytes. J Thromb Haemost (2016) 14(1):191-204. doi:10.1111/jth.13173

170. Zeerleder S, van Bijnen S, Wouters D, van Mierlo GJ, Muus P. Neutrophil extracellular trap formation in $\mathrm{PNH}$ patients with and without a history of thrombosis - effects of eculizumab. Blood (2013) 122(21):1235.

171. Gavillet M, Martinod K, Renella R, Harris C, Shapiro NI, Wagner DD, et al. Flow cytometric assay for direct quantification of neutrophil extracellular traps in blood samples. Am J Hematol (2015) 90(12):1155-8. doi:10.1002/ ajh. 24185

Conflict of Interest Statement: The authors declare that the research was conducted in the absence of any commercial or financial relationships that could be construed as a potential conflict of interest.

Copyright (c) 2017 Mitsios, Arampatzioglou, Arelaki, Mitroulis and Ritis. This is an open-access article distributed under the terms of the Creative Commons Attribution License (CC BY). The use, distribution or reproduction in other forums is permitted, provided the original author(s) or licensor are credited and that the original publication in this journal is cited, in accordance with accepted academic practice. No use, distribution or reproduction is permitted which does not comply with these terms. 